\title{
Simulation of solar PV system by FLC based bidirectional DC- DC converter for DC loads
}

\author{
Srinivasa Rao Jalluri, Ramesh Babu Veligatla, Ranjit Mahamkali, and Purushothama Raghavendra Reddy Gogireddy \\ Vallurupalli Nageswara Rao Vignana Jyothi Institute of Engineering and Technology, EEE Department, Hyderabad, India
}

\begin{abstract}
Solar energy is among the abundant forms of energy, it is very important to make the best use of it. But intermittent nature of solar energy makes PV generation unreliable at times. The use of a battery as an energy storage device can help to mitigate this problem to some extent. A Bidirectional DC-DC converter must be used to connect the battery to the DC link in order to maintain a steady voltage. DC link then connected to a load. In this paper, P\&O MPPT technique used to get maximum power from PV array. Fuzzy logic control is used for the effective control of Bidirectional DC-DC converter to charge and discharge battery to keep the DC link voltage constant. Simulations are carried out using MATLAB and outcomes are analysed.
\end{abstract}

\section{INTRODUCTION}

As traditional sources of energy become depleted, it is very important to employ renewable energy sources like wind, solar energy for power generation. With technological advancements in power electronics field, various power electronic converters can be used to address many applications at desired power levels. Since solar energy is finest among the available energy sources, we can use it for power generation for many applications and also connect it to grid when needed. Solar energy has the advantages like less pollution, ecofriendly, less maintenance and can be used for multiple applications like water heating, maintaining room temperature etc.

With these advantages, one of the main issues with solar energy is its intermittency. Solar energy is highly fluctuating and its difficult to maintain constant voltage at DC link. It is in this situation, energy storage devices and Power electronic converters comes into picture. With the help of energy storage device and Power electronic converters, constant voltage can be maintained at DC link.

The following is breakdown of the work:

Modelling of Solar PV cells covered in subsection 1.1. Subsection 1.2 covers SPV with Boost converter employing Perturb\& Observe MPPT technique to obtain duty cycle. Section 2 covers Proposed Block diagram, Bidirectional converter and PI controller. Controlling a Bidirectional DC-DC converter with Fuzzy is covered in

$$
I_{p v}=I_{p h}-I_{d}
$$

$\mathrm{I}_{\mathrm{ph}}$ is photon current given as
Section 3. Section 4 includes results and analysis of proposed work. Section 5 covers conclusion and future scope of the work.

The objective here is to model Solar PV System with FLC based Bidirectional DC-DC Converter for DC Loads.

1.To design a solar PV system

2.To design Boost converter with MPPT Algorithm

3.To design a Bidirectional DC-DC converter

4.To regulate constant $\mathrm{DC}$ link voltage with Bidirectional DC converter using PI and FL controllers.

\subsection{MODELLING OF SOLAR PV CELL}

Fig.1 shows the model circuit of PV cell. PV cell acts as current source shown as $\mathrm{I}_{\mathrm{ph}}$ gives current produced with movement of electrons, holes when light falls on the cell. Diode $I_{d}$ is in parallel to source and $R_{\text {sh }}$ (shunt resistance) indicates leakage current because of impurities in junction diode. Rs,(series resistance) because of metallic contacts of semiconductor[1]. $\mathrm{V}_{\text {oc }}$ gives the open circuit voltage that is voltage produced from $\mathrm{PN}$ junction diode. $\mathrm{I}_{\mathrm{sc}}$ gives short circuit that gives us value of photon current in SC condition. In Fig(1), applying Kirchhoff's rule,

$$
I_{p h}=\left[\left(I_{s c}+\alpha\left(T-T_{r e f}\right)\right]\left(\beta / \beta_{r e f}\right)\right.
$$

Where,

$\mathrm{I}_{\mathrm{ph}}$ - photon current in A

$\mathrm{I}_{\mathrm{sc}}$ - photon current at $\mathrm{T}_{\text {ref }}=298 \mathrm{~K}, \beta_{\mathrm{ref}}=1000 \mathrm{~W} / \mathrm{m}^{2}$

$\alpha$ - Temperature coefficient 


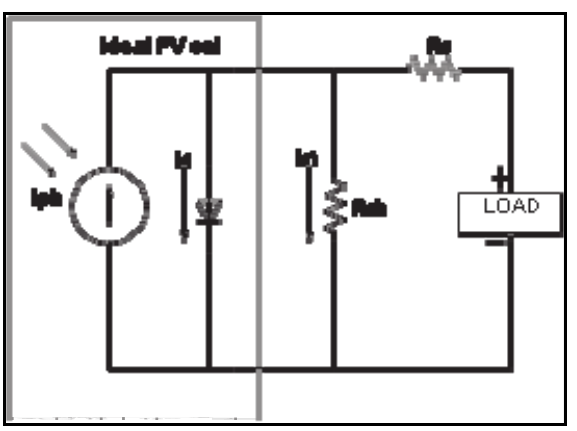

Fig. 1. Model circuit of PV cell

Diode current, $I_{d}$ is given in the equation

$$
I_{d}=I_{s}\left(e^{q v / n k T}-1\right)
$$

Where $I_{s}(A)$ gives the saturation current of diode, $q$ is the charge of the electron $\left(1.6^{*} 10^{-19} \mathrm{C}\right), \mathrm{n}$ is ideality factor, $\mathrm{k}$ represents Boltzmann constant $\left(1.381 * 10^{-23} \mathrm{~J} / \mathrm{K}\right)$ and $\mathrm{T}$ represents absolute temperature in $\mathrm{K}$.

Saturation current of diode depends on the temperature as follows:

$$
I_{S}=I_{o}\left(T / T_{r e f}\right)^{3} e^{q V g / n k}\left(\frac{1}{T}-\frac{1}{T_{r e f}}\right)
$$

$\mathrm{I}_{0}$ gives reverse saturation current $(\mathrm{A}), \mathrm{V}_{\mathrm{g}}$ is bandgap of semiconductor in $\mathrm{V}$.

Keeping $\mathrm{I}_{\mathrm{pv}}=0$ and constant temperature conditions in (1), it can be transformed into

$$
I_{s c}=I_{s}\left(e^{q v / n k T}-1\right)
$$

From (1) PV current is written as

$$
I_{p v}=I_{p h}-I_{S}\left(e^{q v / n k T}-1\right)
$$

As voltage across diode is voltage of PV cell

$$
I_{p v}=I_{p h}-I_{s}\left(e^{q V p v / n k T}-1\right)
$$

And output current is written as follows

$$
I_{p v}=\left[I_{s c}+\alpha\left(T-T_{r e f}\right)\right]\left(\beta / \beta_{r e f}\right)-I_{s}\left(e^{q V p v / n k T}-1\right)
$$

A PV cell can be simulated in MATLAB platform using aforementioned equations[2].

$\mathrm{PV}$ array simulation is comparable to PV cell simulation.

At reference temperature ,equation(6) can be written as

$$
I_{p v}=I_{s c}\left(\beta / \beta_{r e f}\right)-I_{s}\left(e^{q V p v / n k T}-1\right)
$$

For simulation of PV array above equation can be rewritten as

$$
\left(I_{p v} / N p\right)=I_{s c}\left(\beta / \beta_{r e f}\right)-I_{s}\left(e^{q V p v / n k T N s}-1\right)
$$

Table 1 gives the information about specifications used to model Solar PV cell in this work. Fig.2 represents Simulink model of PV cell.

Table 1. Parameters used for the simulation of PV cell are as follows

\begin{tabular}{|c|c|}
\hline Specifications & Values \\
\hline Open Circuit Voltage -Voc & $205 \mathrm{~V}$ \\
\hline Short Circuit Current -Isc & $8.15 \mathrm{~A}$ \\
\hline Band Gap Voltage & $1.1 \mathrm{~V}$ \\
\hline Ideality Factor of diode & 1.3 \\
\hline Series resistance & $0.221 \Omega$ \\
\hline Shunt Resistance & $415.40 \Omega$ \\
\hline
\end{tabular}

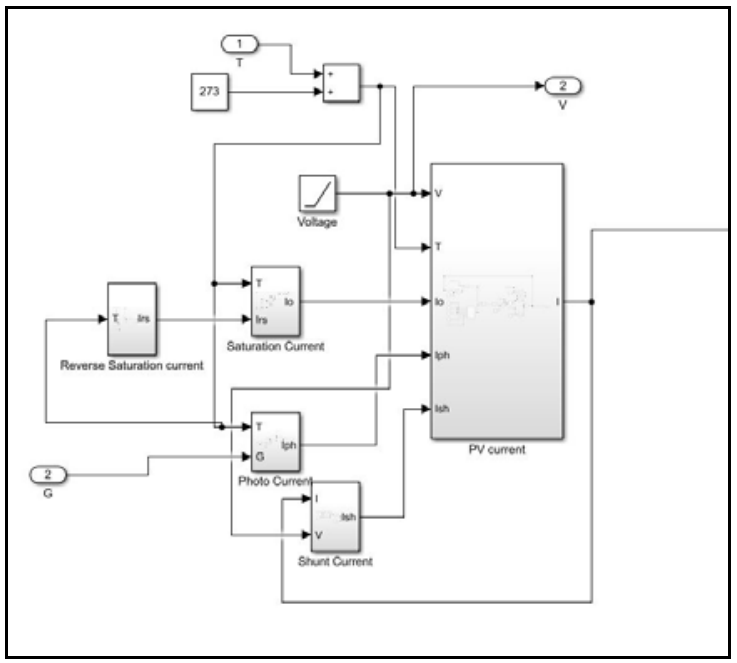

Fig. 2. Simulink circuit of PV Cell

\subsection{BOOST CONVERTER WITH P\&O MPPT}

The use of Maximum Power Point Tracking techniques is critical when renewable energy sources are employed. As Solar PV is intermittent in nature, With variation of ambient temperature, irradiance level and the load, Solar PV array output becomes non-linear. Maximum Power Point Tracking(MPPT) is process of determining effective PV output consistently so that PV array operating point is nearer maximum power point.

There are numerous MPPT techniques available. Some of them are Perturbed\& Observe, Incremental Conductance, Fractional current, feedback control. In this work, Perturb and Observe process used for finding MPPT. Itis simple to apply. Disadvantage in this method in case of sudden variation of solar irradiance, this method may not yield proper results.Fig.3 represents flowchart of Perturb \& Observe method algorithm[3]. 


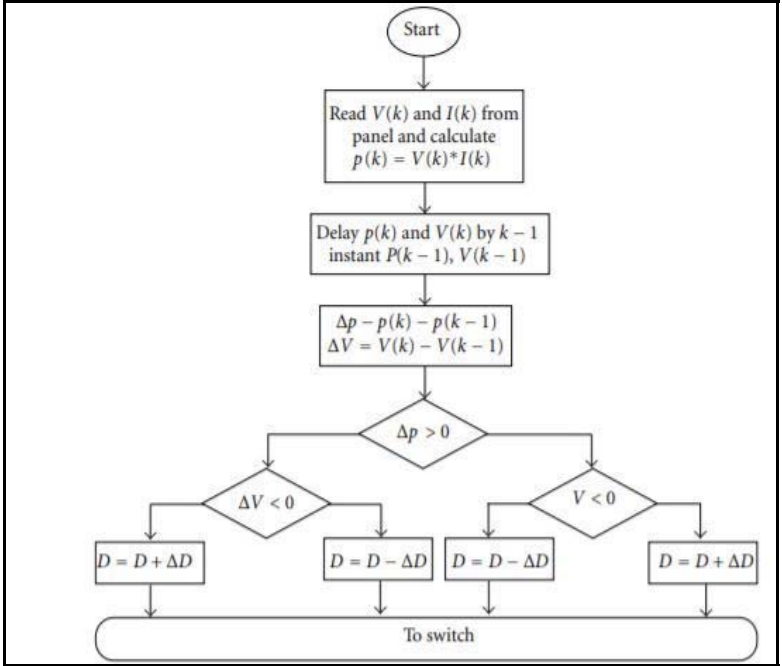

Fig. 3. $\mathrm{P} \& \mathrm{O}$ Flowchart

As the solar PV output is usually low in many cases, Boost converter required to increase voltage for matching requirements in applications[9]. Table 2 shows the specifications used for Boost Converter. Values of inductor, capacitor are determined by the below formula:

$$
\begin{aligned}
& L=\left(V_{p v} * d\right) /\left(\Delta I^{*} f\right) \\
& C=\left(I_{0} * d\right) /\left(\Delta V^{*} f\right)
\end{aligned}
$$

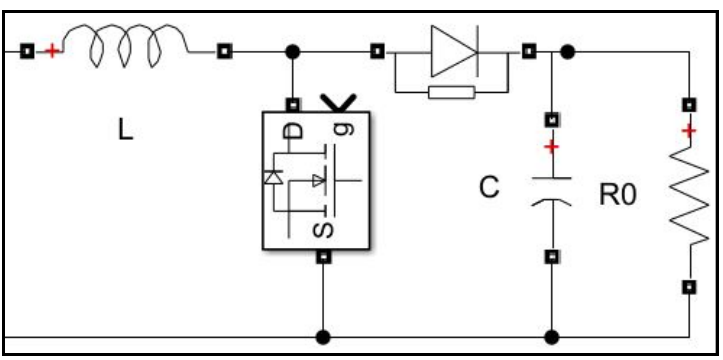

Fig. 4. Boost converter circuit

Table 2. Specifications for Boost converter

\begin{tabular}{|c|c|}
\hline Specifications & Value \\
\hline VDC LINK & $600 \mathrm{~V}$ \\
\hline Frequency & $20 \mathrm{kHz}$ \\
\hline INDUCTANCE(L) & $26.6 \mathrm{mH}$ \\
\hline CAPACITANCE(C) & $25 \mu \mathrm{F}$ \\
\hline
\end{tabular}

Boost converter switch is controlled by output obtained from using $\mathrm{P} \& \mathrm{O}$ process. Fig.5 is Simulink model of Solar PV array with Boost Converter. Solar PV-SPV array output current, voltage are tracked, then duty cycle is obtained using $\mathrm{P} \& \mathrm{O}$ algorithm[3].This duty cycle is then compared with a repeating sequence and the output pulses are connected to switch of Boost converter circuit.

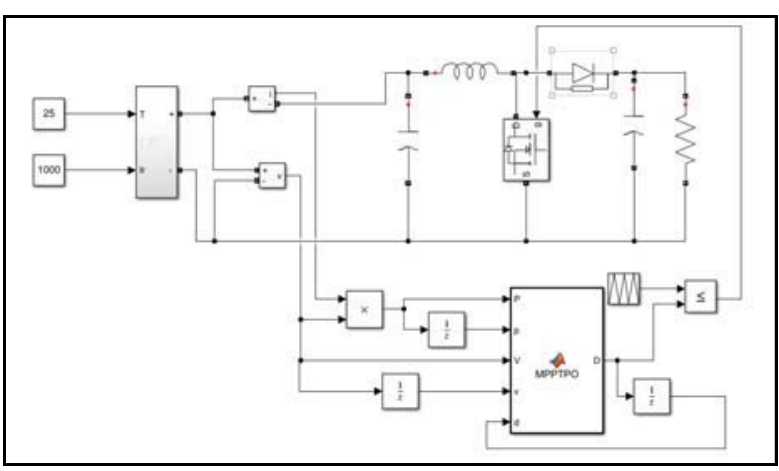

Fig. 5. Simulink model of Solar PV cell with Boost converter

Simulations are carried out for two different values of $\mathrm{R}=120 \mathrm{ohm}, 480 \mathrm{ohm}$.

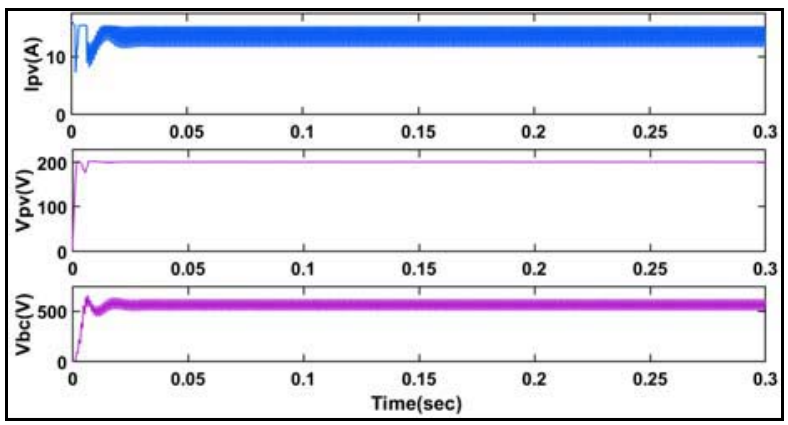

Fig. 6. Output waveforms with $\mathrm{R}=120 \mathrm{ohm}$

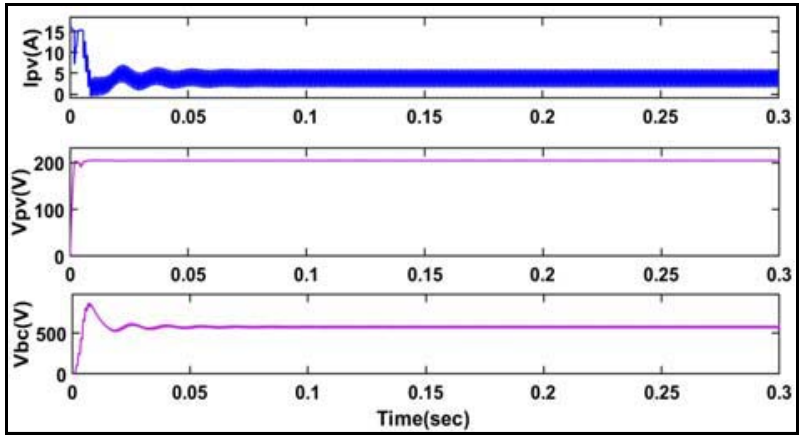

Fig. 7. Output Waveforms with $\mathrm{R}=480 \mathrm{ohm}$

\section{Proposed Block Diagram}

Fig.8 shows proposed Block. It consists PV array, Boost Converter, Bidirectional Converter, a load connected across DC link. Battery is linked to Bidirectional DC-DC converter that charges or discharges battery to keep the voltage constant across DC link[5]. Bidirectional Converter can be controlled using PI or Fuzzy Logic. Table 3 gives information about parameters needed for Bidirectional Converter[2]. 


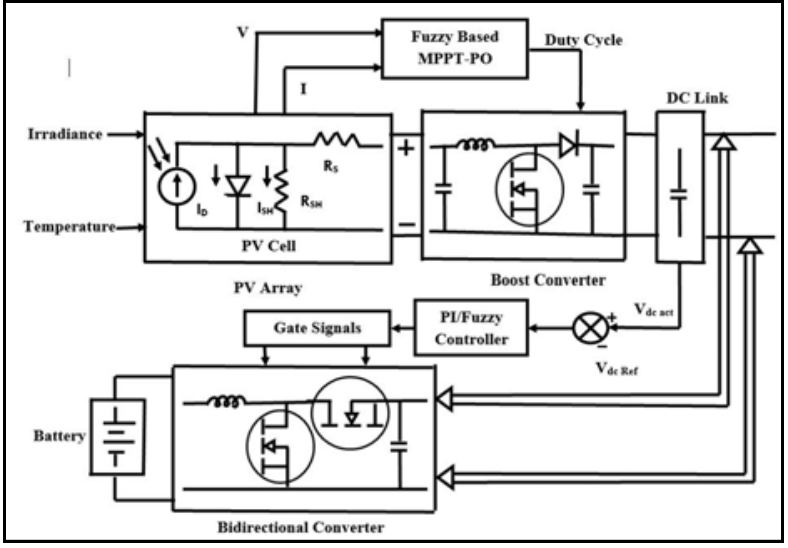

Fig. 8. Proposed Block Diagram

Below are the equations that can be used for calculating inductor and capacitor values for the Bidirectional DC-DC converter based on requirements:

$$
\begin{aligned}
& L=\left(V_{\text {bus }}-V_{\text {battery }}\right) * d /\left(\Delta I^{*} f\right) \\
& C=(\Delta I) /\left(8^{*} \Delta V^{*} f\right)
\end{aligned}
$$

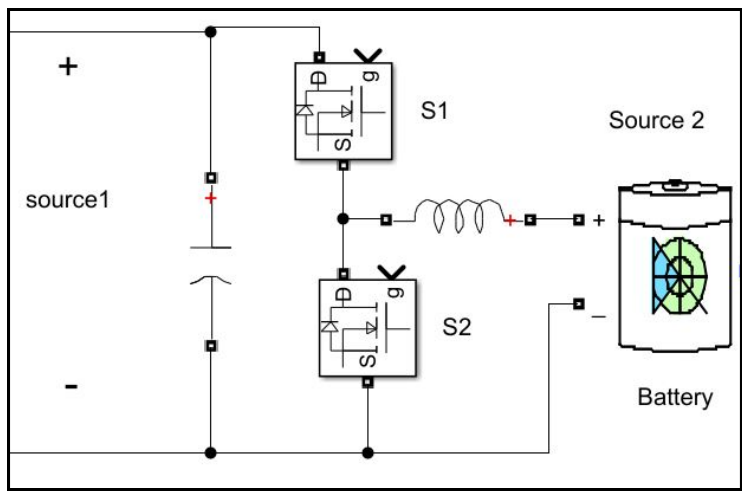

Fig. 9. Bidirectional DC-DC converter circuit

Table 3. Specifications for Bidirectional Converter

\begin{tabular}{|c|c|}
\hline Specifications & Value \\
\hline V $_{\text {DC LINK }}$ & $600 \mathrm{~V}$ \\
\hline V $_{\text {BATTERY }}$ & $240 \mathrm{~V}$ \\
\hline INDUCTANCE(L) & $14 \mathrm{mH}$ \\
\hline CAPACITANCE(C) & $100 \mu \mathrm{F}$ \\
\hline
\end{tabular}

Reference[2] suggests control of switches of Bidirectional converter by PI controller circuit. Fig.10 represents Simulink model of PI control circuit used. Voltage of DC link is measured and compared to reference and the difference given to PI block. Output is a reference current. Battery current is taken and compared to above output and difference is given to another PI block. Here, PI output is fed to pulse generator and pulses are given to both switches of Bidirectional Converter.

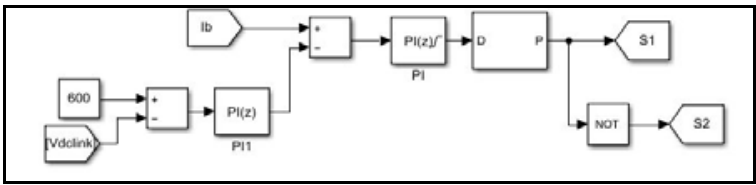

Fig. 10. Simulink Diagram of PI controller

Simulations are carried out for three different values of $\mathrm{R}=120 \mathrm{ohm}, 480 \mathrm{ohm}$.

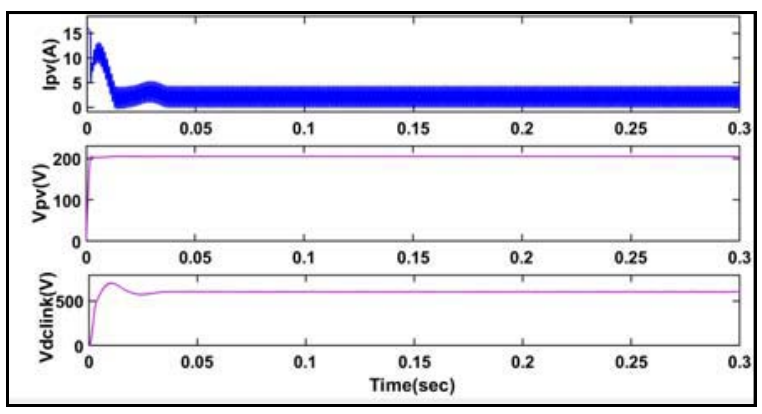

Fig. 11. Output Waveforms When $R=120 \mathrm{ohm}$

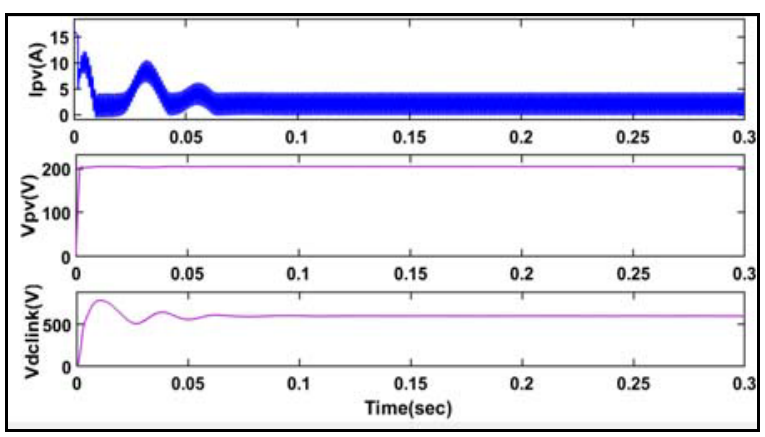

Fig. 12. Output waveforms when $\mathrm{R}=480 \mathrm{ohm}$

\section{FUZZY LOGIC CONTROL}

Fuzzy Introduction: Fuzzy Logic can be employed when there is uncertainty in the system and parameters[6]. Fuzzy system is unlike crisp or Boolean Logic. When the values are not exactly one or zero, Fuzzy system comes into the picture. It is similar to that of how human brain manages inaccurate information. This is an advantage when compared with other controller methods. Important parts of Fuzzy Logic controller are membership functions, if-then rules.

Fuzzy Logic controller contains three steps mainly,

1.Fuzzification

2.Fuzzy Inference Engine

3.Defuzzification

Fuzzification is modification of inputs into fuzzy values based on the knowledge base[7]. Fuzzification involves membership functions. Both inputs and outputs can be modelled into membership functions. In this work, inputs of Fuzzy Logic Controller are,

1.Error between DC link voltage and reference voltage

2.Change in Error

Output of Fuzzy logic controller-FLC is duty cycle. 
Membership functions used in this work are:

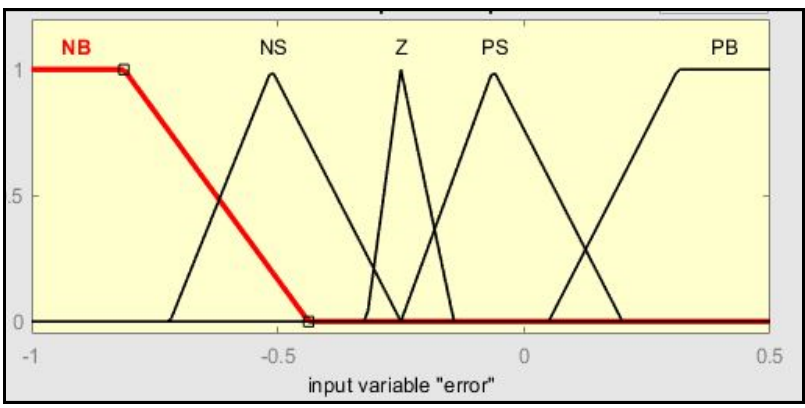

Fig. 13. Error Membership Function

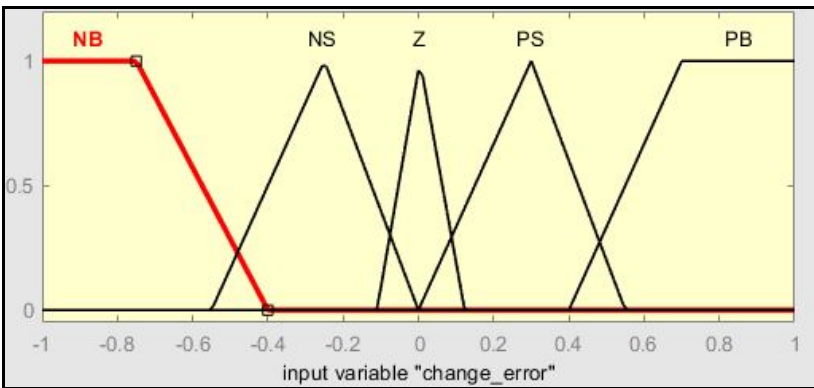

Fig. 14. Change in error Membership Function

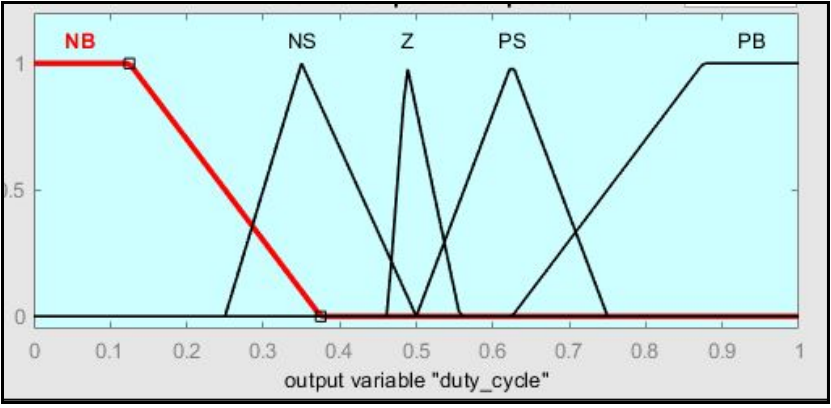

Fig. 15. Duty Cycle Membership function plots

Fuzzy Inference Engine contains if-then rules based on which the output varies. Number of if-then rules knowledge base depends on number of membership functions used. More the number of rules, more will be the precision.

Difference between reference voltage and actual DC link voltage is sensed and given to Fuzzy Inference Engine as one input. The other input is the difference between present error and previous error. Memory block can be used for storing the previous error value. These both inputs are given to Fuzzy Inference Engine. Output bbtained depends on rules written.

In this work, 5 membership functions(MF) are used for error, change in error and Duty cycle. So, Total number of if-then rules are 25 .

Simulations are carried out for two different values of resistance (120ohm and $480 \mathrm{ohm}$ respectively).

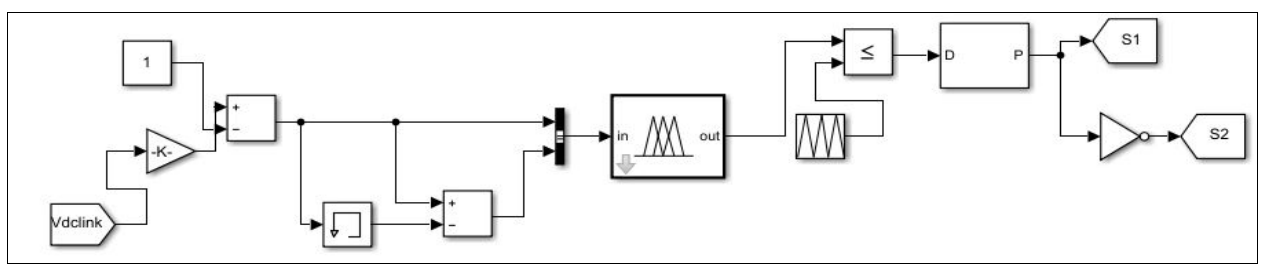

Fig. 16. Simulink Block of Fuzzy Logic Controller

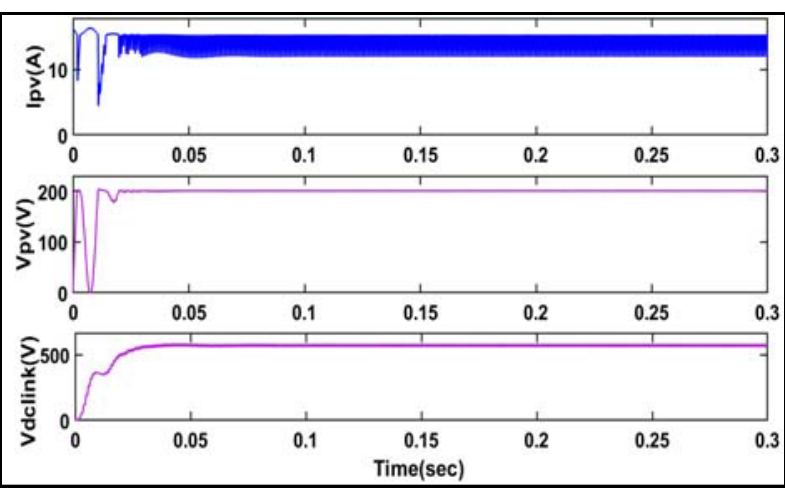

Fig. 17. Output Waveforms with FLC when $R=120 \mathrm{ohm}$

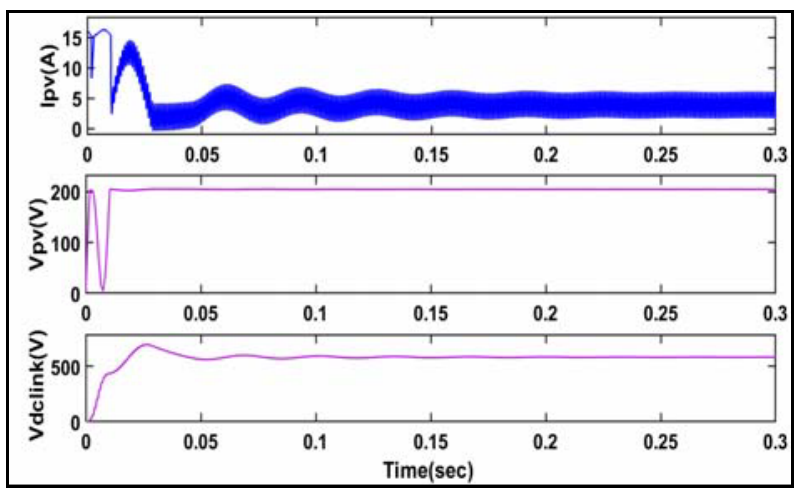

Fig. 18. Output Waveforms when $R=480 \mathrm{ohm}$

\section{RESULTS AND ANALYSIS}

Fig.6 and Fig.7 shows the output waveforms of Boost Converter and DC link voltage when $\mathrm{R}=120 \mathrm{ohm}$ and 
$480 \mathrm{ohm}$ respectively. It can be seen that with variation in the value of resistance, the DC link is varied. Hence to maintain constant DC link voltage irrespective of variations, an energy storage in combination to Bidirectional Converter is necessary. However there are various ways of controlling the converter switches. Here an attempt has been made to show the difference between performance of PI and Fuzzy Logic controllers in controlling Bidirectional converter to keep constant voltage across DC link point.Fig.11 and Fig.12 shows the output waveforms and DC link voltage when $\mathrm{R}=120 \mathrm{ohm}$ and $480 \mathrm{ohm}$ respectively with PI controller.Fig.17 and Fig.18 shows the output waveform and DC link voltage when $\mathrm{R}=120 \mathrm{ohm}$ and $480 \mathrm{ohm}$ with Fuzzy Logic Controller. When $\mathrm{R}=480 \mathrm{ohm}$, Peak voltage when PI controller is employed is around $785 \mathrm{~V}$ when the reference voltage stands at $600 \mathrm{~V}$.

Hence the overshoot $\%$ is 30.83 . In case of Fuzzy Logic Controller, when $\mathrm{R}=480 \mathrm{ohm}$, Peak voltage is around $695 \mathrm{~V}$. Hence the overshoot $\%$ is decreased to around $15 \%$.Also there is a little improvement in settling time in case of FLC than that of Proportional Integral controller.

\section{CONCLUSION AND FUTURE SCOPE OF WORK}

With these results and analysis, it summarizes FLC improves the performance and maintains constant voltage better when compared with PI controller for the same load. DC link can be further connected to inverter and thus output can be taken to AC loads. Using the appropriate methods, a solar PV system can effectively be integrated with the grid.

\section{REFERENCES}

1. Cemal Keles, B. Baykant Alagoz, Murat Akcin, Asim Kaygusuz and Abdulkerim Karabiber," A Photovoltaic system model For MATLAB/Simulink simulations," 4th International Conference on Power Engineering, Energy and Electrical Drives,13-17 May,(2013), pp. 1643-1647

2. Dinanath Prasad, Narendra Kumar and Rakhi Sharma, " Modelling and Simulation of Microgrid Solar Photovoltaic System with Energy Storage," 2nd IEEE International conference on power Electronics, Intelligent Control and Energy systems (ICPEICES-22018), (2018), pp. 623-629.

3. Saurabh Thakran, Jaspreet Singh, Prof. Rachan Garg and Dr. Priya Mahajan, "Implementation of P\&O Algorithm for MPPT in SPV System" 2018 International Conference on Power Energy, Environment and Intelligent Control (PEEIC),13-14 April (2018),pp. 242-245.

4. B. Y. Li, C. Xu, C. Li and Z. Guan, "Working principle analysis and control algorithm for bidirectional DC/DC converter," Journal of Power Technologies 97 (4), (2017), pp. 327-335.

5. Kuei-Hsiang Chao, Ming-Chang Tseng, Chun-Hao Huang, Yang-Guang Liu and Liang-Chiao Huang, "Design and Implementation of a Bidirectional DCDC Converter for Stand-Alone Photovoltaic Systems," International Journal of Computer, Consumer and Control (IJ3C), vol. 2, no.3,(2013), pp.44-55.

6. Anupam Khandelwal, Dr. Jagdish Kumar, "Applications of AI for Power Electronics and Drives Systems: A Review," Innovations in Power and Advanced Computing Technologies (i-PACT), (2019), pp. 1-6.

7. Chetan P. Ugale, R. B. Dhumale and V. V. Dixit," DC-DC Converter Using Fuzzy Logic Controller," International Research Journal of Engineering and Technology (IRJET), pp. 593-596.

8. Rajeshree Patil and Harsha Anantwar, "Comparative analysis of Fuzzy based MPPT for buck and boost converter," International Conference on Smart Technology for Smart Nation, (2017), pp. 1479-1484.

9. Renu kadali, Srinivasa Rao Jalluri, "Design and simulation of boost converter for correction of power factor and THD correction," proceedings of ICMEET,vol-471,(2017). 